\title{
Review Article \\ Innovative Dental Stem Cell-Based Research Approaches: The Future of Dentistry
}

\author{
Shayee Miran, Thimios A. Mitsiadis, and Pierfrancesco Pagella \\ Orofacial Development and Regeneration, Institute of Oral Biology, Centre for Dental Medicine, \\ University of Zurich, 8032 Zurich, Switzerland \\ Correspondence should be addressed to Pierfrancesco Pagella; pierfrancesco.pagella@zzm.uzh.ch
}

Received 11 April 2016; Revised 15 June 2016; Accepted 12 July 2016

Academic Editor: Bernard A. J. Roelen

Copyright (C) 2016 Shayee Miran et al. This is an open access article distributed under the Creative Commons Attribution License, which permits unrestricted use, distribution, and reproduction in any medium, provided the original work is properly cited.

Over the past decade, the dental field has benefited from recent findings in stem cell biology and tissue engineering that led to the elaboration of novel ideas and concepts for the regeneration of dental tissues or entire new teeth. In particular, stem cell-based regenerative approaches are extremely promising since they aim at the full restoration of lost or damaged tissues, ensuring thus their functionality. These therapeutic approaches are already applied with success in clinics for the regeneration of other organs and consist of manipulation of stem cells and their administration to patients. Stem cells have the potential to self-renew and to give rise to a variety of cell types that ensure tissue repair and regeneration throughout life. During the last decades, several adult stem cell populations have been isolated from dental and periodontal tissues, characterized, and tested for their potential applications in regenerative dentistry. Here we briefly present the various stem cell-based treatment approaches and strategies that could be translated in dental practice and revolutionize dentistry.

\section{Introduction}

Repair of dental pulp and periodontium remains an immense clinical challenge since human teeth have a very limited capacity to regenerate [1]. Current therapeutic interventions in dentistry are based on sophisticated biomaterials and implants with still questionable efficacy and durability [2-5]. Moreover, these therapies do not always allow the appropriate physiological function of the tooth organ. Therefore, there is an enormous unmet need for innovative methods enabling a balance between new dental tissue formation and unaltered physiological functions of the tooth organ $[6,7]$.

In order to reconstruct such natural structures we need to have a deep knowledge of the cellular and molecular events linked to odontogenesis. Classical experiments have shown that teeth form as a result of sequential and reciprocal interactions between cells of the oral epithelium and neural crest-derived mesenchyme [8]. Epithelial cells differentiate into enamel-forming ameloblasts, while mesenchymal cells give rise to the dental pulp, the dentin-secreting odontoblasts, and the periodontal ligament cells that anchor the tooth to the surrounding alveolar bone $[8,9]$. The dental pulp forms a connective tissue that conveys vascularization and innervation and hosts stem cells that are capable of regenerating this tissue, as well as the dentin [1]. Sensory nerves from the trigeminal ganglia (TG) and sympathetic nerves from the superior cervical ganglia innervate the adult teeth [1012]. During odontogenesis, nerve fibers emanate from the TG project towards the developing tooth germs and progressively surround them without entering the dental pulp. The first axons penetrate the dental pulp when odontoblasts differentiate and enamel deposition starts. Dental pulp innervation is completed soon after tooth eruption into the oral cavity [10], a process that is concomitant with root growth, cementum matrix deposition, and periodontium formation [7].

A common issue in dental practice is the infection and the subsequent extirpation of the dental pulp. Since structures and cells within the dental pulp provide trophic support, sensation, and defense against the various pathogens, devitalized teeth (e.g., after classical endodontic therapy) are subject to severe complications that cause tooth fragility and fracture [13]. It becomes thus evident that the maintenance 


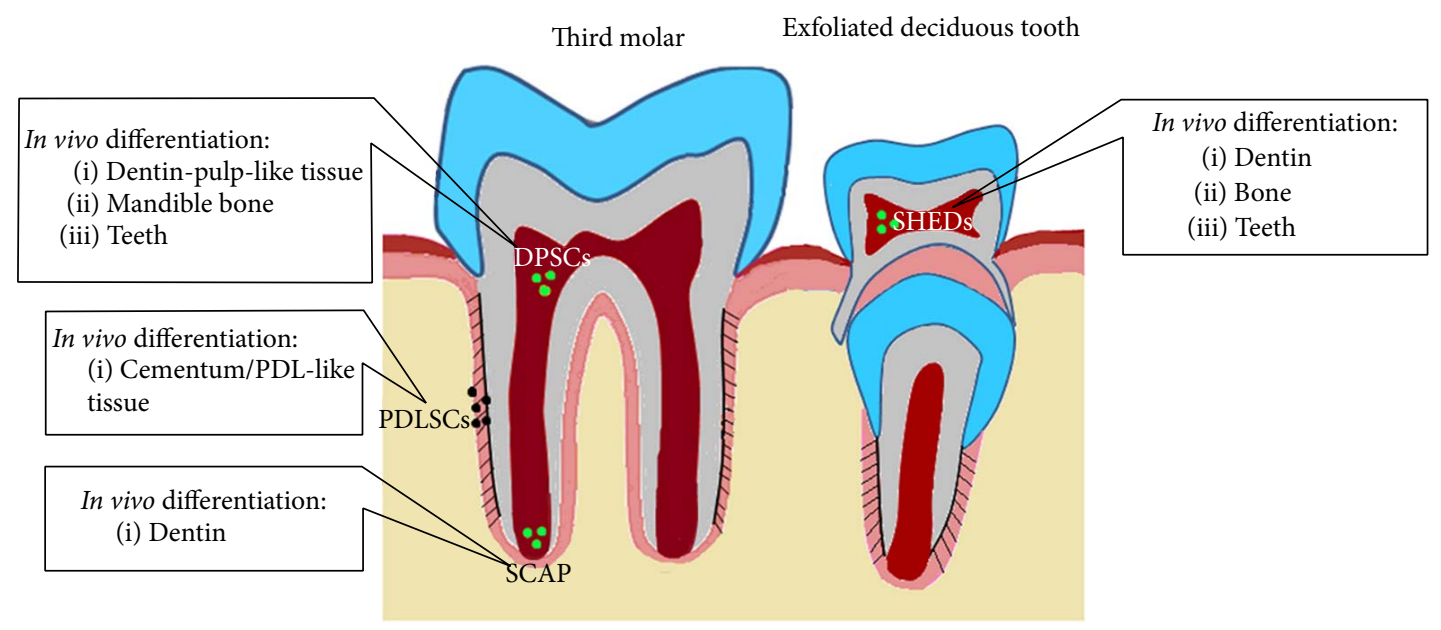

FIGURE 1: Schematic representation of the main stem cell sources in the human teeth and their differentiation potential in vivo. DPSCs: dental pulp stem cells, SHEDs: stem cells from human exfoliated deciduous teeth, PDLSCs: periodontal ligament stem cells, and SCAP: stem cells from the apical part of the papilla.

of dental pulp vitality is of prime importance and therefore new regenerative approaches have started to be experimented in endodontic clinics in the last few years [14]. These new regenerative techniques could also apply in other dental disciplines, where current treatment options are based on a constantly increasing number of dental biomaterials and implants [1-4]. For example, tooth loss caused after severe traumatic injuries, periodontitis (i.e., a severe inflammation of the periodontium), advanced carious lesions, age-related alternations, or cancer $[6,7,15-19]$ could be resolved by whole new tooth regeneration.

\section{Stem Cell-Based Regenerative Dentistry}

Regeneration involves the replacement of a pathologic tissue, as well as the reconstruction of a missing or lost tissue, by a new one that can ensure its biological function [20]. Regenerative approaches are based on the potential of human stem cells to self-renew and give rise to a diversity of cell types under appropriate conditions [21]. Throughout life, adult stem cells support tissue homeostasis and repair upon injury $[6,22,23]$. Therefore, adult stem cells from different tissues have been isolated, characterized, and tested for their potential applications in regenerative medicine [20]. In particular, mesenchymal stem cells (MSCs) have been the subject of intense investigation due to their accessibility and their potential to differentiate towards the chondrogenic, osteogenic, adipogenic, myogenic, and neurogenic lineages [24].

Different stem cell populations have been isolated from human adult teeth (Figure 1). The dental pulp of third molars is the most common source of dental mesenchymal stem cells, the so called dental pulp stem cells (DPSCs) [25]. Human DPSCs are able to differentiate into odontoblasts, osteoblasts, adipocytes, chondrocytes, and other cell types both in vitro and in vivo [26-28]. Other populations of dental MSCs (i.e., SHEDs) have been isolated from dental pulp of exfoliated deciduous teeth and from the apical part of the papilla (i.e., SCAPs), similar to the DPSCs differentiation potential [29-31]. Dental MSCs have been also isolated from the periodontal ligament (i.e., periodontal ligament stem cells, PDLSCs) that have the capacity to give rise to cementum/PDL-like tissue in vivo $[32,33]$.

The behavior and properties of stem cells are strongly influenced by the surrounding environment, the so-called stem cell niche $[24,34,35]$. This specific microenvironment is a combination of cells, extracellular matrix, and growth factors that is under the influence by mechanical and chemical stresses [24]. Niches maintain and regulate the balance between stem cell self-renewal and differentiation [35]. In this context, considerable effort is produced to understand how the different components of the niches regulate stem cell function. Among these actors, innervation could play an important role in the fate and function of stem cells [36-42], thus affecting regenerative events. For example, recent studies have shown that parasympathetic nerves regulate progenitor cells and are necessary for the development and regeneration of the salivary glands $[37,39]$. Similarly, it has been demonstrated that innervation is essential for the development and maintenance of taste buds [43-46]. Although the role of innervation in the initiation, development, and regeneration of teeth is still highly controversial [34, 47-49], it has been recently shown that sensory nerves regulate MSCs in mouse incisors [42]. Therefore, it is important to better study the role of innervation in tooth regeneration and most particularly its effect in dental stem cell populations. At the same time, it is of equal importance to ensure proper reinnervation of the regenerated dental tissues. Vascularization represents another key aspect of tooth regeneration. The dental pulp is richly vascularized, and teeth depend on blood supply for nutrients and oxygen transport. In addition, blood vessels allow the transport of systemic signals and the recruitment of inflammatory and other circulatory cells into the niches that can strongly affect stem cell function [35]. Blood vessels 


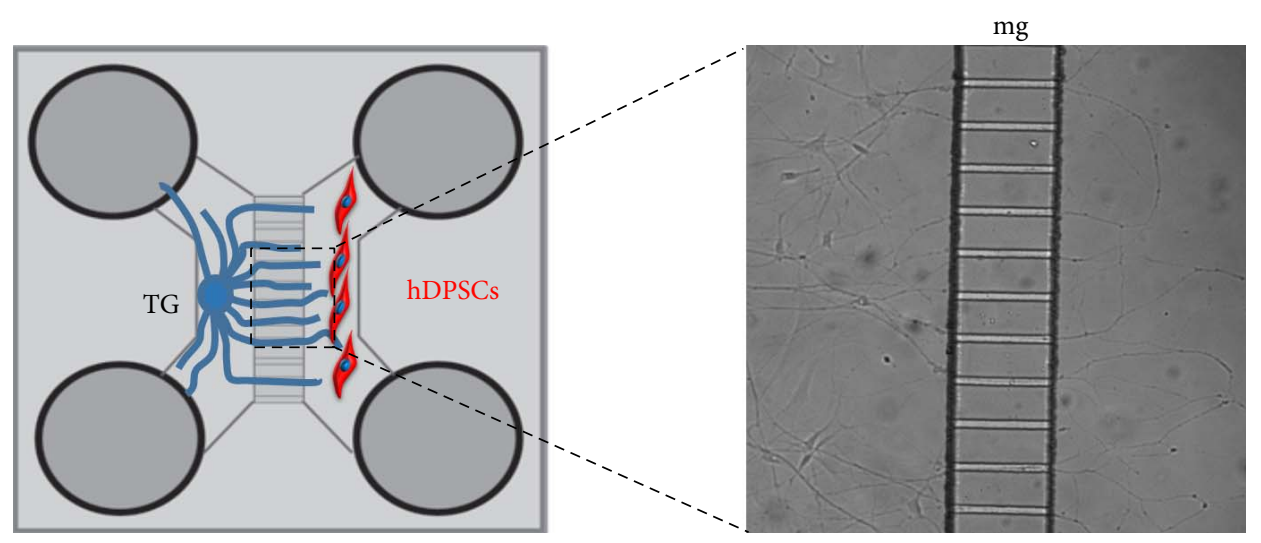

FIGURE 2: Schematic representation of coculture between trigeminal ganglia (TG) and human dental pulp stem cells (hDPSCs) through microfluidic devices. In this system, both cell types/tissues are cultured in optimal conditions, while allowing the growth of trigeminal ganglia axons through microgrooves (mg) to innervate the stem cells.

within the pulp are associated with the so-called perivascular stem cell niches. These niches host MSCs that contribute to the homeostasis and the regeneration of the dental pulp [42, 50]. The growth of blood vessels and nerves often proceeds in parallel, sharing the same paths through tissues [51]. Teeth are peculiar organs in the sense that innervation and vascularization display extremely divergent timing. While blood vessels are found in the pulp of tooth germs during early developmental stages, innervation is established only at late stages of odontogenesis $[6,52]$. As both innervation and vascularization are fundamental for tooth physiology and pathology, the identification of the mechanisms that regulate these two processes will be fundamental in the light of partial (e.g., pulp regeneration) or full tooth regeneration.

Several in vivo and in vitro studies have provided important information about the patterns of innervation of dental tissues in different animal models as well as the main molecules involved in nerve trophic support, repulsion, and attraction $[10,53-56]$. To date, little information is available concerning the effects of innervation on human dental stem cells [57]. Cocultures have been used and constitute a valuable method to investigate and manipulate the interactions between nerve fibers and target tissues of human origin in a controlled and isolated environment (Figure 2) [57, 58]. The use of these and other state-of-the-art techniques, in combination with in vivo approaches in animal models, will allow gaining fundamental knowledge regarding the role of innervation in stem cell behavior and the mechanisms that drive tooth reinnervation [6]. To date, only very few studies investigating the possibility of restoring innervation in damaged teeth have been conducted [59].

Pulp revascularization is currently used as a method for its regeneration in not yet fully developed teeth [59]. In this approach, pulp revascularization is induced by filling the empty root canal with a blood clot. Although already in the clinical practice, this method is characterized by low efficiency and by ectopic mineralization within the pulp [59]. Moreover, a major issue that accompanies these revascularization approaches is the connection with the circulation system [59]. Tissue engineering approaches that exploit combinations of functionalized scaffolds and dental stem cells are providing promising results, ensuring variable degrees of pulp regeneration and vascularization in vivo in animal models [60-62]. In these studies, good vascularization and connection with the circulatory system were observed, thus suggesting that such approaches could ensure proper trophic support to the regenerated dental tissues $[60,61]$.

\section{Clinical Implications: How the Knowledge Obtained from These Approaches Could Be Used}

Stem cell-based therapies are very promising long-term alterative in dentistry since they could offer full restoration of dental tissues keeping thus the structural integrity, physiology, and function of the intact teeth. In vivo studies in animals have demonstrated the potential of different tooth stem cells populations for the regeneration of specific dental tissues, such as dentin, pulp, periodontium, or even the entire tooth organ $[59,60,63-66]$ (Figure 3). These regenerative approaches that have been successfully tested in animal models could be also applied to humans. It is obvious that these treatments will necessitate a sufficient number of specific stem cell populations that will be transplanted to damaged and pathological dental sites, alone or together with scaffolds.

It is worth noting that stem cell-based approaches have already started to be applied with success in other medical disciplines [67-70]. In dentistry, several specialties took advantage of the recent progress in the fields of stem cell biology and tissue engineering and developed innovative strategies for restoring the full function and physiology of specific dental tissues. For example, regenerative endodontics focuses on reestablishment of dental pulp vitality and new dentin formation using DPSCs/SCAPs combined with scaffolds loaded with bioactive molecules [26, 71-75]. These new procedures allow the transplanted stem cells to differentiate 


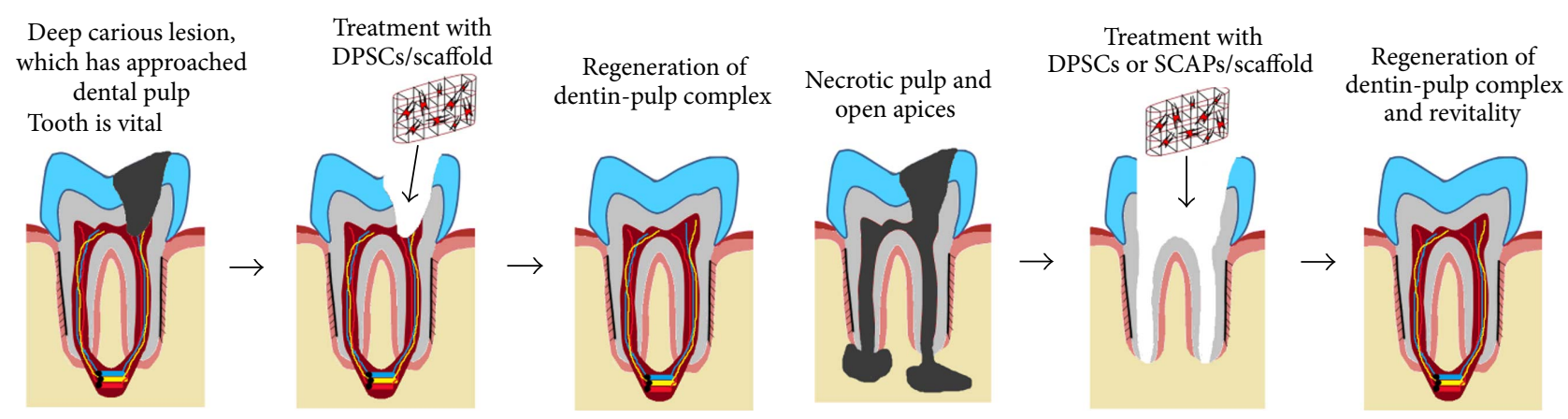

(a)

(b)

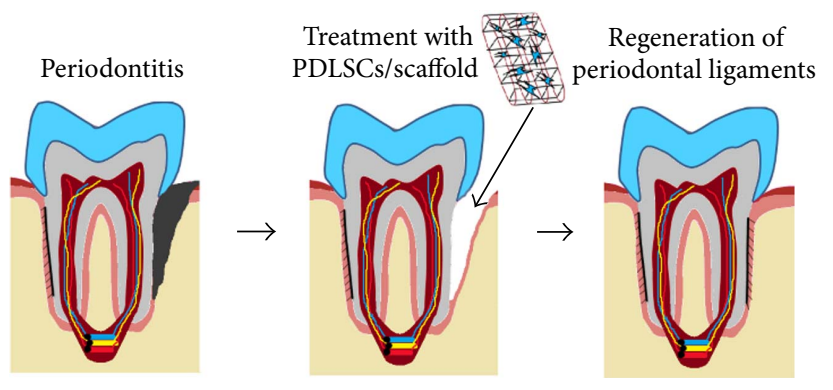

(c)

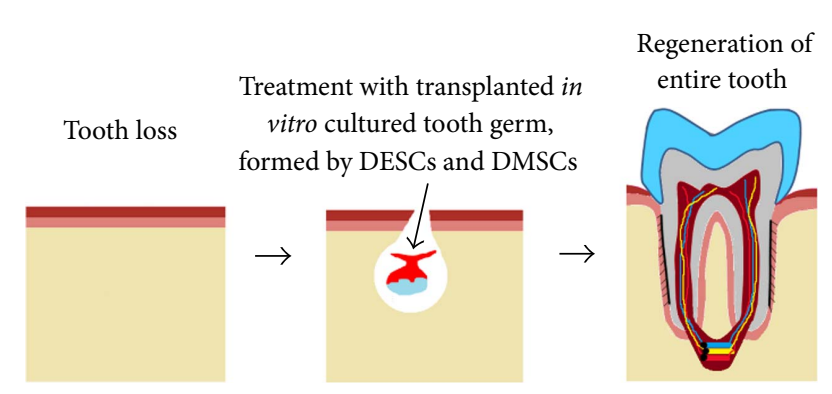

(d)

FIGURE 3: Schematic representation of different stem cell-based approaches for partial or whole tooth regeneration after pathologies and tooth loss using transplantation of tooth stem cells combined with scaffolds. The various dental pathologies: (a) carious lesion, (b) necrotic pulp, (c) periodontitis, and (d) tooth loss. DPSCs, dental pulp stem cells; PDLSCs, periodontal ligament stem cells; SCAP, stem cells from the apical part of the papilla; DESCs, dental epithelial stem cells; DMSCs, dental mesenchymal stem cells.

into pulp fibroblasts and odontoblasts and progressively fill the empty pulp chamber after pulpotomy or pulpectomy, thus allowing root growth in not yet fully developed teeth $[63,71,76-78]$ (Figure 3). Several clinical attempts based on the bleeding technique and focused in pulp regeneration have been successfully applied in immature teeth with pulp necrosis and mature teeth with apical lesions [71, 78-80]. In this procedure, the blood clot acts as a scaffold that delivers stem cells into the empty root canal.

Although the use of stem cell-based techniques has started to be applied in endodontic clinics, these approaches are still at the animal experimental level for other dental specialties such as in periodontology. For example, while the potential of human PDLSCs or other stem cell populations for periodontal tissue regeneration has been evidenced in animal models [81-84], there are not equivalent trials yet in clinics (Figure 3).

Similarly, although attempts for the regeneration of entire brand new teeth have been successfully performed the last few years in small animal models $[85,86]$ dental implants still monopolize and offer the therapeutic solution after tooth loss in clinics. However, it is obvious that the ideal therapy after tooth loss would be the regeneration of an entire tooth, and therefore a bigger effort should be produced towards these revolutionary stem cell-based approaches. These novel techniques tested in mice have shown that dental mesenchymal and epithelial stem cells combined with collagen drops or scaffolds in vitro allows the formation of tooth germs that thereafter could be transplanted into the alveolar bone, where the tooth germs will develop, erupt, and finally become entire functional teeth $[85,86]$ (Figure 3 ). The application of this technique in humans has some limitations. The biggest challenge is the time needed for human tooth regeneration, since the whole process of odontogenesis in humans takes more than 7 years $[1,17]$. This may represent a discouragement for patients looking for a quick replacement of the missing teeth.

\section{Conclusion}

Stem cell-based therapies represent the most promising alternative for successful regeneration of damaged or pathological dental tissues or even the entire tooth following tooth loss. It is therefore fundamental to understand the exact mechanisms underlying the potential of the various dental stem cell populations as well as their behavior after transplantation in ectopic sites. Innervation and vascularization play fundamental roles in the regulation of stem cell niches homeostasis, thus affecting the fate and behavior of stem cells $[34,87]$. Therefore, it would be of great interest to further investigate the role of innervation in these processes. Stem cell-based approaches are only starting to emerge in dentistry, and huge challenges and problems such the enamel and entire tooth regeneration should be overcome. The majority of the experimental attempts mentioned above were exclusively performed in small animal models and thus they cannot be 
directly translated into the clinics yet. Nevertheless, stem cellbased regenerative approaches are the future of dentistry that will benefit millions of patients worldwide.

\section{Competing Interests}

The authors declare no conflict of interests.

\section{Authors' Contributions}

All authors equally contributed to the planning, writing, critical reading, and editing of the present paper.

\section{Acknowledgments}

This work was supported by funds of the University of Zurich.

\section{References}

[1] T. A. Mitsiadis, G. Orsini, and L. Jimenez-Rojo, "Stem cell-based approaches in dentistry," European Cells and Materials, vol. 30, pp. 248-257, 2015.

[2] R. Adell, B. Eriksson, U. Lekholm, P. I. Brånemark, and T. Jemt, "Long-term follow-up study of osseointegrated implants in the treatment of totally edentulous jaws," The International Journal of Oral \& Maxillofacial Implants, vol. 5, no. 4, pp. 347-359, 1990.

[3] J. Catón, N. Bostanci, E. Remboutsika, C. De Bari, and T. A. Mitsiadis, "Future dentistry: cell therapy meets tooth and periodontal repair and regeneration," Journal of Cellular and Molecular Medicine, vol. 15, no. 5, pp. 1054-1065, 2011.

[4] T. B. Dodson, "Predictors of dental implant survival," Journal of the Massachusetts Dental Society, vol. 54, no. 4, pp. 34-38, 2006.

[5] L. Jiménez-Rojo, Z. Granchi, A. Woloszyk, A. Filatova, P. Pagella, and T. A. Mitsiadis, Regenerative Dentistry: Stem Cells meet Nanotechnology, chapter 1, Pan Stanford, Boca Raton, Fla, USA, 2016.

[6] P. Pagella, E. Neto, M. Lamghari, and T. A. Mitsiadis, "Investigation of orofacial stem cell niches and their innervation through microfluidic devices," European Cells and Materials, vol. 29, pp. 213-223, 2015.

[7] T. A. Mitsiadis and H. Harada, "Regenerated teeth: the future of tooth replacement. An update," Regenerative Medicine, vol. 10, no. 1, pp. 5-8, 2015.

[8] T. A. Mitsiadis and D. Graf, "Cell fate determination during tooth development and regeneration," Birth Defects Research Part C: Embryo Today: Reviews, vol. 87, no. 3, pp. 199-211, 2009.

[9] A. Nanci, Ten Cate's Oral Histology: Development, Structure, and Function, Elsevier, Louis, Mo, USA, 8th edition, 2013.

[10] S. S. Mohamed and M. E. Atkinson, "A histological study of the innervation of developing mouse teeth," Journal of Anatomy, vol. 136, no. 4, pp. 735-749, 1983.

[11] K. Luukko, "Immunohistochemical localization of nerve fibres during development of embryonic rat molar using peripherin and protein gene product 9.5 antibodies," Archives of Oral Biology, vol. 42, no. 3, pp. 189-195, 1997.

[12] D. C. Johnsen, "Innervation of teeth: qualitative, quantitative, and developmental assessment," Journal of Dental Research, vol. 64, pp. 555-563, 1985.
[13] D. Ricketts, "Management of the deep carious lesion and the vital pulp dentine complex," British Dental Journal, vol. 191, no. 11, pp. 606-610, 2001.

[14] P. D. Potdar and Y. D. Jethmalani, "Human dental pulp stem cells: applications in future regenerative medicine," World Journal of Stem Cells, vol. 7, no. 5, pp. 839-851, 2015.

[15] J. J. Mao, P. G. Robey, and D. J. Prockop, "Stem cells in the face: tooth regeneration and beyond," Cell Stem Cell, vol. 11, no. 3, pp. 291-301, 2012.

[16] E. L. Scheller, P. H. Krebsbach, and D. H. Kohn, "Tissue engineering: state of the art in oral rehabilitation," Journal of Oral Rehabilitation, vol. 36, no. 5, pp. 368-389, 2009.

[17] T. A. Mitsiadis and P. Papagerakis, "Regenerated teeth: the future of tooth replacement?," Regenerative Medicine, vol. 6, no. 2, pp. 135-139, 2011.

[18] P. Marec-Berard, D. Azzi, A. G. Chaux-Bodard, H. Lagrange, R. Gourmet, and C. Bergeron, "Long-term effects of chemotherapy on dental status in children treated for nephroblastoma," Pediatric Hematology and Oncology, vol. 22, no. 7, pp. 581-588, 2005.

[19] E. Matalova, J. Fleischmannova, P. T. Sharpe, and A. S. Tucker, "Tooth agenesis: from molecular genetics to molecular dentistry," Journal of Dental Research, vol. 87, no. 7, pp. 617-623, 2008.

[20] L. Jiménez-Rojo, Z. Granchi, A. Woloszyk, A. Filatova, P. Pagella, and T. A. Mitsiadis, Regenerative Dentistry: Stem Cells meet Nanotechnology, chapter 1, Pan Standford, 2009.

[21] A. Uccelli, L. Moretta, and V. Pistoia, "Mesenchymal stem cells in health and disease," Nature Reviews Immunology, vol. 8, no. 9, pp. 726-736, 2008.

[22] H. M. Blau, T. R. Brazelton, and J. M. Weimann, “The evolving concept of a stem cell: entity or function?” Cell, vol. 105, no. 7, pp. 829-841, 2001.

[23] Y. D. Zhang, Z. Chen, Y. Q. Song, C. Liu, and Y. P. Chen, "Making a tooth: growth factors, transcription factors, and stem cells," Cell Research, vol. 15, no. 5, pp. 301-316, 2005.

[24] T. A. Mitsiadis, O. Barrandon, A. Rochat, Y. Barrandon, and C. De Bari, "Stem cell niches in mammals," Experimental Cell Research, vol. 313, no. 16, pp. 3377-3385, 2007.

[25] G. T.-J. Huang, S. Gronthos, and S. Shi, "Mesenchymal stem cells derived from dental tissues vs. those from other sources: their biology and role in regenerative medicine," Journal of Dental Research, vol. 88, no. 9, pp. 792-806, 2009.

[26] S. Gronthos, M. Mankani, J. Brahim, P. G. Robey, and S. Shi, "Postnatal human dental pulp stem cells (DPSCs) in vitro and in vivo," Proceedings of the National Academy of Sciences of the United States of America, vol. 97, no. 25, pp. 13625-13630, 2000.

[27] S. Batouli, M. Miura, J. Brahim et al., "Comparison of stem-cellmediated osteogenesis and dentinogenesis," Journal of Dental Research, vol. 82, no. 12, pp. 976-981, 2003.

[28] R. D’Aquino, A. De Rosa, V. Lanza et al., "Human mandible bone defect repair by the grafting of dental pulp stem /progenitor cells and collagen sponge biocomplexes," European Cells and Materials, vol. 18, pp. 75-83, 2009.

[29] M. Miura, S. Gronthos, M. Zhao et al., "SHED: stem cells from human exfoliated deciduous teeth," Proceedings of the National Academy of Sciences of the United States of America, vol. 100, no. 10, pp. 5807-5812, 2003.

[30] M. M. Cordeiro, Z. Dong, T. Kaneko et al., "Dental pulp tissue engineering with stem cells from exfoliated deciduous teeth," Journal of Endodontics, vol. 34, no. 8, pp. 962-969, 2008. 
[31] W. Sonoyama, Y. Liu, D. Fang et al., "Mesenchymal stem cellmediated functional tooth regeneration in Swine," PLOS ONE, vol. 1, article e79, 2006.

[32] B.-M. Seo, M. Miura, S. Gronthos et al., "Investigation of multipotent postnatal stem cells from human periodontal ligament," The Lancet, vol. 364, no. 9429, pp. 149-155, 2004.

[33] L. Wang, H. Shen, W. Zheng et al., "Characterization of stem cells from alveolar periodontal ligament," Tissue EngineeringPart A, vol. 17, no. 7-8, pp. 1015-1026, 2011.

[34] P. Pagella, L. Jiménez-Rojo, and T. A. Mitsiadis, "Roles of innervation in developing and regenerating orofacial tissues," Cellular and Molecular Life Sciences, vol. 71, no. 12, pp. 2241-2251, 2014.

[35] D. L. Jones and A. J. Wagers, "No place like home: anatomy and function of the stem cell niche," Nature Reviews Molecular Cell Biology, vol. 9, no. 1, pp. 11-21, 2008.

[36] S. Méndez-Ferrer, D. Lucas, M. Battista, and P. S. Frenette, "Haematopoietic stem cell release is regulated by circadian oscillations," Nature, vol. 452, no. 7186, pp. 442-447, 2008.

[37] S. M. Knox, I. M. A. Lombaert, X. Reed, L. Vitale-Cross, J. S. Gutkind, and M. P. Hoffman, "Parasympathetic innervation maintains epithelial progenitor cells during salivary organogenesis," Science, vol. 329, no. 5999, pp. 1645-1647, 2010.

[38] E. Martínez-Martínez, C. I. Galván-Hernández, B. ToscanoMárquez, and G. Gutiérrez-Ospina, "Modulatory role of sensory innervation on hair follicle stem cell progeny during wound healing of the rat skin," PloS one, vol. 7, no. 5, Article ID e36421, 2012.

[39] S. M. Knox, I. M. A. Lombaert, C. L. Haddox et al., "Parasympathetic stimulation improves epithelial organ regeneration," Nature Communications, vol. 4, article 1494, 2013.

[40] Y. Katayama, M. Battista, W.-M. Kao et al., "Signals from the sympathetic nervous system regulate hematopoietic stem cell egress from bone marrow," Cell, vol. 124, no. 2, pp. 407-421, 2006.

[41] I. Brownell, E. Guevara, C. B. Bai, C. A. Loomis, and A. L. Joyner, "Nerve-derived sonic hedgehog defines a niche for hair follicle stem cells capable of becoming epidermal stem cells," Cell Stem Cell, vol. 8, no. 5, pp. 552-565, 2011.

[42] H. Zhao, J. Feng, K. Seidel et al., "Secretion of shh by a neurovascular bundle niche supports mesenchymal stem cell homeostasis in the adult mouse incisor," Cell Stem Cell, vol. 14, no. 2, pp. 160-173, 2014.

[43] B. Oakley and M. Witt, "Building sensory receptors on the tongue," Journal of Neurocytology, vol. 33, no. 6, pp. 631-646, 2005.

[44] B. Oakley, A. Brandemihl, D. Cooper, D. Lau, A. Lawton, and C. Zhang, "The morphogenesis of mouse vallate gustatory epithelium and taste buds requires BDNF-dependent taste neurons," Developmental Brain Research, vol. 105, no. 1, pp. 8596, 1998.

[45] H. Sun and B. Oakley, "Development of anterior gustatory epithelia in the palate and tongue requires epidermal growth factor receptor," Developmental Biology, vol. 242, no. 1, pp. 3143, 2002.

[46] C. M. Mistretta, K. A. Goosens, I. Farinas, and L. F. Reichardt, "Alterations in size, number, and morphology of gustatory papillae and taste buds in BDNF null mutant mice demonstrate neural dependence of developing taste organs," Journal of Comparative Neurology, vol. 409, no. 1, pp. 13-24, 1999.
[47] S. Løes, P. Kettunen, I. Kvinnsland, and K. Luukko, "Mouse rudimentary diastema tooth primordia are devoid of peripheral nerve fibers," Anatomy and Embryology, vol. 205, no. 3, pp. 187191, 2002.

[48] A. G. S. Lumsden and J. A. G. Buchanan, "An experimental study of timing and topography of early tooth development in the mouse embryo with an analysis of the role of innervation," Archives of Oral Biology, vol. 31, no. 5, pp. 301-311, 1986.

[49] E. J. Kollar and A. G. S. Lumsden, “Tooth morphogenesis: the role of the innervation during induction and pattern formation," Journal de Biologie Buccale, vol. 7, no. 1, pp. 49-60, 1979.

[50] M. Oh and J. E. Nör, "The perivascular niche and self-renewal of stem cells," Frontiers in Physiology, vol. 6, article 367, 2015.

[51] P. Carmeliet and M. Tessier-Lavigne, "Common mechanisms of nerve and blood vessel wiring," Nature, vol. 436, no. 7048, pp. 193-200, 2005.

[52] A. Nait Lechguer, S. Kuchler-Bopp, B. Hu, Y. Haïkel, and H. Lesot, "Vascularization of engineered teeth," Journal of Dental Research, vol. 87, no. 12, pp. 1138-1143, 2008.

[53] K. Luukko and P. Kettunen, "Coordination of tooth morphogenesis and neuronal development through tissue interactions: lessons from mouse models," Experimental Cell Research, vol. 325, no. 2, pp. 72-77, 2014.

[54] C. Lillesaar, C. Eriksson, C. S. Johansson, K. Fried, and C. Hildebrand, "Tooth pulp tissue promotes neurite outgrowth from rat trigeminal ganglia in vitro," Journal of Neurocytology, vol. 28, no. 8, pp. 663-670, 1999.

[55] I. V. Nosrat, C. A. Smith, P. Mullally, L. Olson, and C. A. Nosrat, "Dental pulp cells provide neurotrophic support for dopaminergic neurons and differentiate into neurons in vitro; implications for tissue engineering and repair in the nervous system," European Journal of Neuroscience, vol. 19, no. 9, pp. 2388-2398, 2004.

[56] I. V. Nosrat, J. Widenfalk, L. Olson, and C. A. Nosrat, "Dental pulp cells produce neurotrophic factors, interact with trigeminal neurons in vitro, and rescue motoneurons after spinal cord injury," Developmental Biology, vol. 238, no. 1, pp. 120-132, 2001.

[57] P. Pagella, S. Miran, and T. A. Mitsiadis, "Analysis of developing tooth germ innervation using microfluidic co-culture devices," Journal of Visualized Experiments, no. 102, Article ID e53114, 2015.

[58] P. Pagella, E. Neto, L. Jiménez-Rojo, M. Lamghari, and T. A. Mitsiadis, "Microfluidics co-culture systems for studying tooth innervation," Frontiers in Physiology, vol. 5, article 326, 2014.

[59] J. Yang, G. Yuan, and Z. Chen, "Pulp regeneration: current approaches and future challenges," Frontiers in Physiology, vol. 7, pp. 1-8, 2016.

[60] X. Li, C. Ma, X. Xie, H. Sun, and X. Liu, "Pulp regeneration in a full-length human tooth root using a hierarchical nanofibrous microsphere system," Acta Biomaterialia, vol. 35, pp. 57-67, 2016.

[61] W. L. Dissanayaka, K. M. Hargreaves, L. Jin, L. P. Samaranayake, and C. Zhang, "The interplay of dental pulp stem cells and endothelial cells in an injectable peptide hydrogel on angiogenesis and pulp regeneration in vivo," Tissue Engineering-Part A, vol. 21, no. 3-4, pp. 550-563, 2015.

[62] K. M. Galler, J. D. Hartgerink, A. C. Cavender, G. Schmalz, and R. N. D'Souza, "A customized self-assembling peptide hydrogel for dental pulp tissue engineering," Tissue Engineering-Part A, vol. 18, no. 1-2, pp. 176-184, 2012. 
[63] Y. Zheng, X. Y. Wang, Y. M. Wang et al., "Dentin regeneration using deciduous pulp stem/progenitor cells," Journal of Dental Research, vol. 91, no. 7, pp. 676-682, 2012.

[64] T. Iwata, M. Yamato, H. Tsuchioka et al., "Periodontal regeneration with multi-layered periodontal ligament-derived cell sheets in a canine model," Biomaterials, vol. 30, no. 14, pp. 27162723, 2009.

[65] D. Akita, K. Kano, Y. Saito-Tamura et al., "Use of rat mature adipocyte-derived dedifferentiated fat cells as a cell source for periodontal tissue regeneration," Frontiers in Physiology, vol. 7, pp. 1-12, 2016.

[66] W. Wang, M. Dang, Z. Zhang et al., "Dentin regeneration by stem cells of apical papilla on injectable nanofibrous microspheres and stimulated by controlled BMP-2 release," Acta Biomaterialia, vol. 36, pp. 63-72, 2016.

[67] S. J. Forbes and N. Rosenthal, "Preparing the ground for tissue regeneration: from mechanism to therapy," Nature Medicine, vol. 20, no. 8, pp. 857-869, 2014.

[68] K. Nishida, M. Yamato, Y. Hayashida et al., "Corneal reconstruction with tissue-engineered cell sheets composed of autologous oral mucosal epithelium," The New England Journal of Medicine, vol. 351, no. 12, pp. 1187-1196, 2004.

[69] M. H. Frank and N. Y. Frank, "Restoring the cornea from limbal stem cells," Regenerative Medicine, vol. 10, no. 1, pp. 1-4, 2015.

[70] S. A. Eming, P. Martin, and M. Tomic-Canic, "Wound repair and regeneration: mechanisms, signaling, and translation," Science Translational Medicine, vol. 6, no. 265, Article ID 265sr6, 2014.

[71] V. Chrepa, M. A. Henry, B. J. Daniel, and A. Diogenes, “Delivery of apical mesenchymal stem cells into root canals of mature teeth," Journal of Dental Research, vol. 94, no. 12, pp. 1653-1659, 2015.

[72] O. A. Peters, "Translational opportunities in stem cell-based endodontic therapy: where are we and what are we missing?" Journal of Endodontics, vol. 40, no. 4, pp. S82-S85, 2014.

[73] Y. Hayashi, M. Murakami, R. Kawamura, R. Ishizaka, O. Fukuta, and M. Nakashima, "CXCL14 and MCP1 are potent trophic factors associated with cell migration and angiogenesis leading to higher regenerative potential of dental pulp side population cells," Stem Cell Research and Therapy, vol. 6, article 111, 2015.

[74] G. T.-J. Huang, T. Yamaza, L. D. Shea et al., "Stem/Progenitor cell-mediated de novo regeneration of dental pulp with newly deposited continuous layer of dentin in an in vivo model," Tissue Engineering-Part A, vol. 16, no. 2, pp. 605-615, 2010.

[75] A. A. Volponi, Y. Pang, and P. T. Sharpe, "Stem cell-based biological tooth repair and regeneration," Trends in Cell Biology, vol. 20, no. 12, pp. 715-722, 2010.

[76] K. Iohara, K. Imabayashi, R. Ishizaka et al., "Complete pulp regeneration after pulpectomy by transplantation of $\mathrm{CD}_{105}{ }^{+}$ stem cells with stromal cell-derived factor-1," Tissue Engineering-Part A, vol. 17, no. 15-16, pp. 1911-1920, 2011.

[77] K. Iohara, M. Murakami, N. Takeuchi et al., "A novel combinatorial therapy with pulp stem cells and granulocyte colonystimulating factor for total pulp regeneration," Stem Cells Translational Medicine, vol. 2, no. 7, pp. 521-533, 2013.

[78] T. W. Lovelace, M. A. Henry, K. M. Hargreaves, and A. Diogenes, "Evaluation of the delivery of mesenchymal stem cells into the root canal space of necrotic immature teeth after clinical regenerative endodontic procedure," Journal of Endodontics, vol. 37, no. 2, pp. 133-138, 2011.
[79] B. S. Deepak and D. B. Nandini, "Stem cells: challenges in endodontics," Journal of Pharmacy and Bioallied Sciences, vol. 4, no. 1, p. 84, 2012.

[80] I. S. Sönmez, A. Akbay Oba, and M. Erkmen Almaz, "Revascularization/regeneration performed in immature molars: case reports," Journal of Clinical Pediatric Dentistry, vol. 37, no. 3, pp. 231-234, 2013.

[81] G. Ding, Y. Liu, W. Wang et al., "Allogeneic periodontal ligament stem cell therapy for periodontitis in swine," Stem Cells, vol. 28, no. 10, pp. 1829-1838, 2010.

[82] J. Du, Z. Shan, P. Ma, S. Wang, and Z. Fan, "Allogeneic bone marrow mesenchymal stem cell transplantation for periodontal regeneration," Journal of Dental Research, vol. 93, no. 2, pp. 183188,2014

[83] X. Fu, L. Jin, P. Ma, Z. Fan, and S. Wang, "Allogeneic stem cells from deciduous teeth in treatment for periodontitis in Miniature Swine," Journal of Periodontology, vol. 85, no. 6, pp. 845-851, 2014.

[84] A. Khorsand, M. B. Eslaminejad, M. Arabsolghar et al., "Autologous dental pulp stem cells in regeneration of defect created in canine periodontal tissue," Journal of Oral Implantology, vol. 39, no. 4, pp. 433-443, 2013.

[85] E. Ikeda and T. Tsuji, "Growing bioengineered teeth from single cells: potential for dental regenerative medicine," Expert Opinion on Biological Therapy, vol. 8, no. 6, pp. 735-744, 2008.

[86] M. Oshima and T. Tsuji, "Functional tooth regenerative therapy: tooth tissue regeneration and whole-tooth replacement," Odontology, vol. 102, no. 2, pp. 123-136, 2014.

[87] A. Kumar and J. P. Brockes, "Nerve dependence in tissue, organ, and appendage regeneration," Trends in Neurosciences, vol. 35, no. 11, pp. 691-699, 2012. 

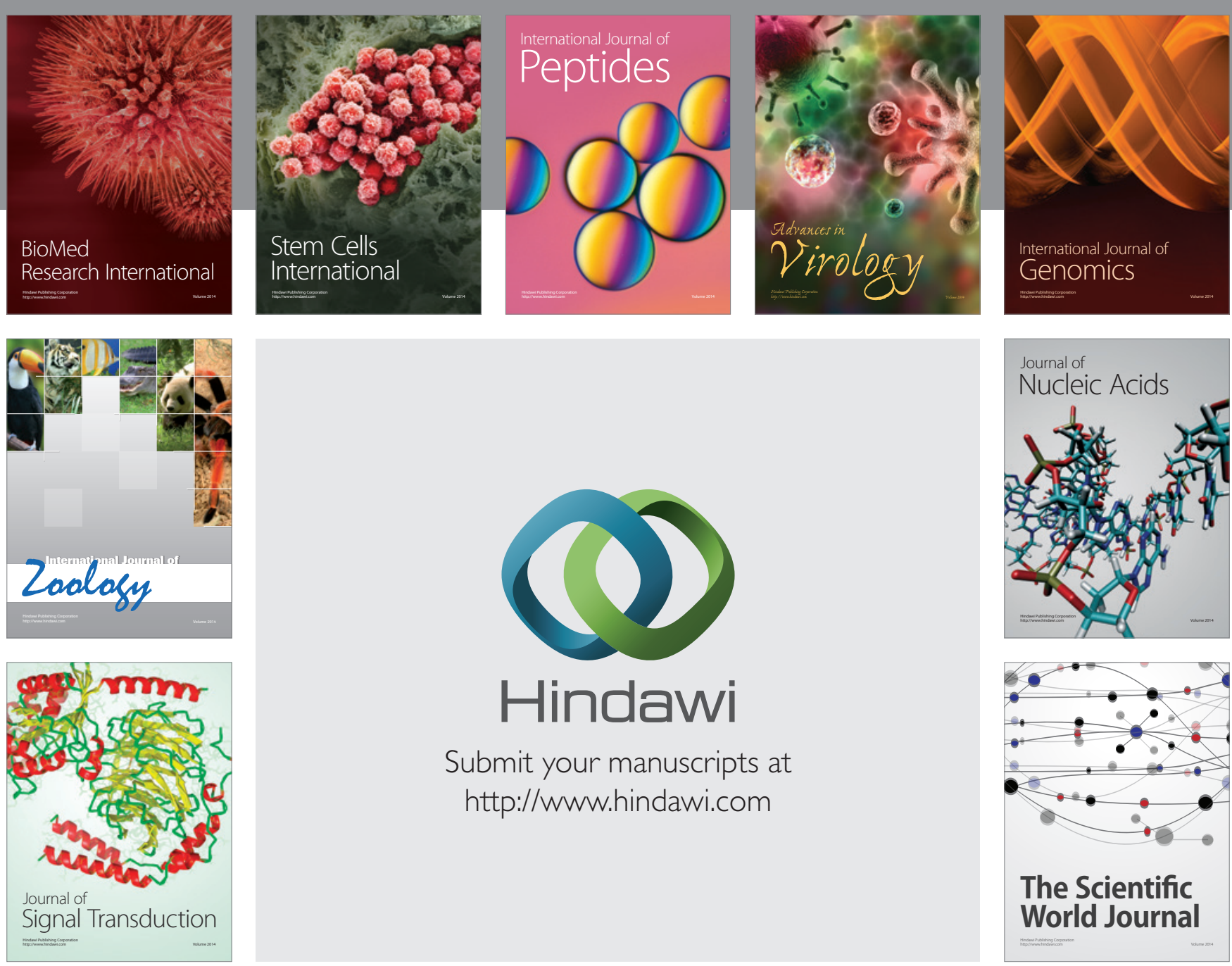

Submit your manuscripts at

http://www.hindawi.com
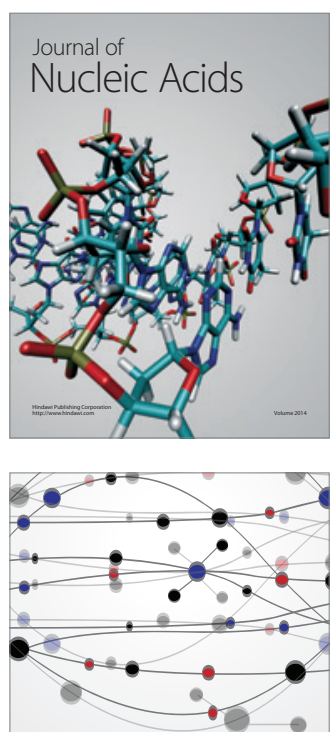

The Scientific World Journal
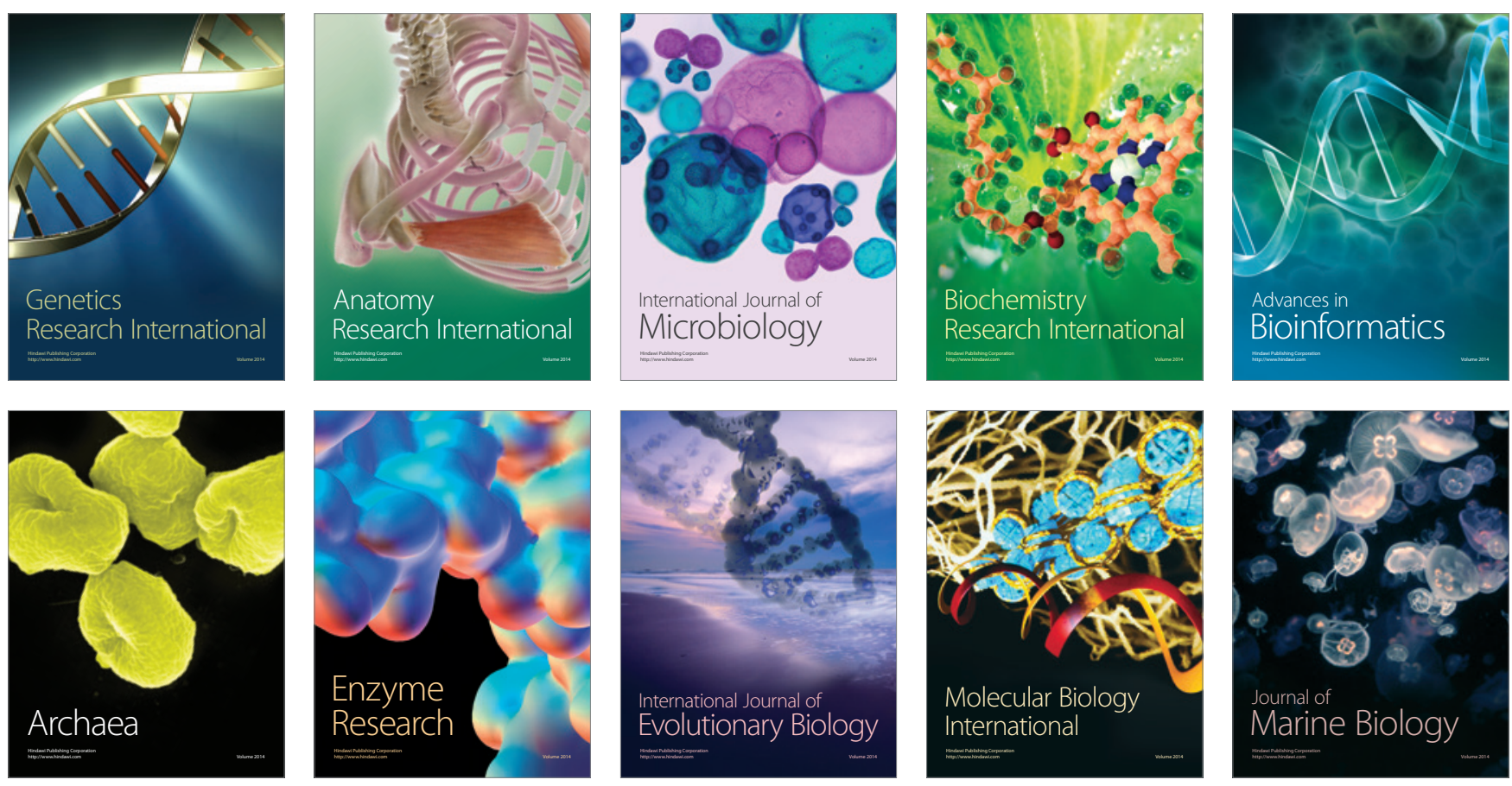